Cultured Construction: Global Evidence of the Impact of National Values on Piped-toPremises Water Infrastructure Development

\author{
Jessica A. Kaminsky ${ }^{*}$
}

*Department of Civil and Environmental Engineering, University of Washington, 201 More Hall, Seattle, WA, 98195. Telephone +1.206.221.3058. Fax +1.206.543.1543. E-mail

jkaminsk@uw.edu.

\title{
LIST OF SUPPORTING INFORMATION
}

2 pages

Table SI1: Change in water infrastructure metrics and Hofstede's cultural dimensions 
Table SI1

\begin{tabular}{|c|c|c|c|c|c|c|c|c|c|c|c|c|c|c|}
\hline Nation & $\mathbf{P D I}^{\mathrm{A}}$ & IDV $^{\mathrm{A}}$ & $\mathbf{M A S}^{\mathbf{A}}$ & $\mathbf{U A I}^{\mathbf{A}}$ & $\begin{array}{c}\text { Water } \\
\text { Per } \\
\text { Capita, } \\
\text { 2012 }^{\mathrm{B}}\end{array}$ & $\begin{array}{c}\text { GDP } \\
\text { Per } \\
\text { Capita, } \\
\text { 2012 }^{\mathrm{C}}\end{array}$ & $\begin{array}{l}\text { \% Change } \\
\text { in Urban } \\
\text { Population, } \\
\text { 1990-2012 }^{\mathrm{D}}\end{array}$ & $\begin{array}{c}\% \\
\text { Change } \\
\text { in } \\
\text { National } \\
\text { Piped to } \\
\text { Premises } \\
\text { Water } \\
\text { Coverage, } \\
1990- \\
2012^{\mathrm{E}} \\
\end{array}$ & $\begin{array}{c}\text { \% Change } \\
\text { in Urban } \\
\text { Piped to } \\
\text { Premises } \\
\text { Water } \\
\text { Coverage, } \\
1990- \\
2012^{\mathrm{E}}\end{array}$ & $\begin{array}{c}\text { \% Change } \\
\text { in Rural } \\
\text { Piped to } \\
\text { Premises } \\
\text { Water } \\
\text { Coverage, } \\
1990- \\
2012^{\mathrm{E}}\end{array}$ & $\begin{array}{c}\% \\
\text { National } \\
\text { Piped to } \\
\text { Premises } \\
\text { Water } \\
\text { Coverage, } \\
1_{1990^{\mathrm{E}}}\end{array}$ & $\begin{array}{c}\text { \% Urban } \\
\text { Piped to } \\
\text { Premises } \\
\text { Water } \\
\text { Coverage, } \\
1_{1990^{E}}\end{array}$ & $\begin{array}{c}\text { \% Rural } \\
\text { Piped to } \\
\text { Premises } \\
\text { Water } \\
\text { Coverage, } \\
1_{1990^{E}}\end{array}$ & $\begin{array}{c}\% \\
\text { Change } \\
\text { in } \\
\text { Improved } \\
\text { Water } \\
\text { Coverage, } \\
1990- \\
2012^{\mathrm{E}}\end{array}$ \\
\hline Argentina & 49 & 46 & 56 & 86 & 7107 & 7831 & 4.3 & 10.3 & 4.0 & 51.5 & 93.6 & 41.4 & 86.8 & 4.9 \\
\hline Bangladesh & 80 & 20 & 55 & 60 & 679 & 684 & 12.2 & 6.3 & 8.8 & 1.0 & 23.1 & 0.0 & 4.6 & 16.8 \\
\hline Brazil & 69 & 38 & 49 & 76 & 28497 & 5901 & 11.0 & 14.9 & 5.6 & 28.8 & 91.6 & 38.4 & 77.8 & 9 \\
\hline Bulgaria & 70 & 30 & 40 & 85 & 2874 & 4730 & 6.6 & 12.2 & 3.1 & 29.7 & 95.8 & 66.1 & 85.8 & -0.4 \\
\hline Chile & 63 & 23 & 28 & 86 & 50673 & 9437 & 5.7 & 11.1 & 2.0 & 53.4 & 97.6 & 37.9 & 87.6 & 8.4 \\
\hline China & 80 & 20 & 66 & 30 & 2083 & 3378 & 25.4 & 40.4 & 8.4 & 39.4 & 77.6 & 10.6 & 28.3 & 25.2 \\
\hline Costa Rica & 35 & 15 & 21 & 86 & 23516 & 5723 & 23.9 & 14.4 & 6.7 & 17.4 & 92.8 & 72.4 & 82.6 & 3.5 \\
\hline Ecuador & 78 & 8 & 63 & 67 & 28556 & 3592 & 8.0 & 24.4 & 15.7 & 31.1 & 75.7 & 38.2 & 58.8 & 12.5 \\
\hline El Salvador & 66 & 19 & 40 & 94 & 2482 & 3033 & 16.1 & 32.6 & 16.0 & 38.5 & 69.7 & 14.8 & 41.8 & 15.3 \\
\hline Estonia & 40 & 60 & 30 & 60 & 9609 & 11821 & -3.4 & 14.3 & 6.8 & 34.3 & 92.6 & 52.4 & 81.1 & -0.1 \\
\hline Finland & 33 & 63 & 26 & 59 & 19764 & 39763 & 4.5 & 5.8 & 3.4 & 15.0 & 96.6 & 84.9 & 94.2 & 0 \\
\hline Greece & 60 & 35 & 57 & 112 & 5229 & 18744 & 5.5 & 5.1 & 0.9 & 15.6 & 99.1 & 84.4 & 94.9 & 3.6 \\
\hline Guatemala & 95 & 6 & 37 & 101 & 7240 & 2315 & 9.1 & 33.2 & 27.9 & 32.6 & 69.2 & 36.9 & 50.2 & 12.4 \\
\hline Hungary & 46 & 80 & 88 & 82 & 605 & 11232 & 4.0 & 11.0 & 3.8 & 25.1 & 93.5 & 73.2 & 86.6 & 4.3 \\
\hline India & 77 & 48 & 56 & 40 & 1169 & 1127 & 6.1 & 10.6 & 6.4 & 8.9 & 46.8 & 6.0 & 16.4 & 22.3 \\
\hline Indonesia & 78 & 14 & 46 & 48 & 8179 & 1723 & 20.9 & 11.1 & 6.4 & 6.3 & 25.3 & 2.3 & 9.3 & 15.2 \\
\hline Ireland & 28 & 70 & 68 & 35 & 10683 & 47286 & 5.5 & 1.8 & 1.7 & 1.9 & 95.9 & 95.8 & 95.9 & 0.1 \\
\hline Japan & 54 & 46 & 95 & 92 & 3371 & 36912 & 14.6 & 4.0 & 1.8 & 9.1 & 96.8 & 85.9 & 94.4 & 0 \\
\hline Lithuania & 42 & 60 & 19 & 65 & 5208 & 10214 & -1.0 & 17.2 & 9.9 & 33.1 & 88.6 & 44.6 & 74.3 & 8.8 \\
\hline Malaysia & 104 & 26 & 50 & 36 & 19836 & 6790 & 22.7 & 19.3 & 12.2 & 19.3 & 87.7 & 64.8 & 76.2 & 11.4 \\
\hline Mexico & 81 & 30 & 69 & 82 & 3384 & 8534 & 7.0 & 15.6 & 9.1 & 27.2 & 85.9 & 49.2 & 75.4 & 12.6 \\
\hline Morocco & 70 & 46 & 53 & 68 & 892 & 2462 & 10.3 & 23.7 & 15.2 & 17.9 & 75.1 & 4.1 & 38.4 & 10.8 \\
\hline Pakistan & 55 & 14 & 50 & 70 & 307 & 769 & 6.9 & 15.0 & 8.4 & 14.2 & 51.3 & 8.7 & 21.7 & 6.1 \\
\hline Panama & 95 & 11 & 44 & 86 & 35926 & 7260 & 11.8 & 10.7 & 1.2 & 17.5 & 95.4 & 62.9 & 80.4 & 10.4 \\
\hline Peru & 64 & 16 & 42 & 87 & 54722 & 3934 & 8.7 & 21.1 & 11.5 & 31.0 & 73.4 & 12.9 & 54.6 & 12.4 \\
\hline Philippines & 94 & 32 & 64 & 44 & 4953 & 1501 & -3.8 & 15.6 & 14.4 & 19.0 & 42.7 & 8.8 & 25.3 & 8.2 \\
\hline
\end{tabular}


Table SI1

\begin{tabular}{|c|c|c|c|c|c|c|c|c|c|c|c|c|c|c|}
\hline Nation & $\mathbf{P D I}^{\mathrm{A}}$ & IDV $^{\mathrm{A}}$ & $\mathbf{M A S}^{\mathbf{A}}$ & $\mathbf{U A I}^{\mathbf{A}}$ & $\begin{array}{c}\text { Water } \\
\text { Per } \\
\text { Capita, } \\
\text { 2012 }^{\mathrm{B}}\end{array}$ & $\begin{array}{c}\text { GDP } \\
\text { Per } \\
\text { Capita, } \\
\text { 2012 }^{\mathrm{C}}\end{array}$ & $\begin{array}{l}\text { \% Change } \\
\text { in Urban } \\
\text { Population, } \\
\text { 1990-2012 }^{\text {D }}\end{array}$ & $\begin{array}{c}\% \\
\text { Change } \\
\text { in } \\
\text { National } \\
\text { Piped to } \\
\text { Premises } \\
\text { Water } \\
\text { Coverage, } \\
1990- \\
2012^{\mathrm{E}} \\
\end{array}$ & $\begin{array}{c}\text { \% Change } \\
\text { in Urban } \\
\text { Piped to } \\
\text { Premises } \\
\text { Water } \\
\text { Coverage, } \\
1990- \\
2012^{\mathrm{E}}\end{array}$ & $\begin{array}{c}\text { \% Change } \\
\text { in Rural } \\
\text { Piped to } \\
\text { Premises } \\
\text { Water } \\
\text { Coverage, } \\
1990- \\
2012^{\mathrm{E}}\end{array}$ & $\begin{array}{c}\% \\
\text { National } \\
\text { Piped to } \\
\text { Premises } \\
\text { Water } \\
\text { Coverage, } \\
\text { 1990 }^{\mathrm{E}}\end{array}$ & $\begin{array}{c}\text { \% Urban } \\
\text { Piped to } \\
\text { Premises } \\
\text { Water } \\
\text { Coverage, } \\
1990^{\mathrm{E}}\end{array}$ & $\begin{array}{c}\text { \% Rural } \\
\text { Piped to } \\
\text { Premises } \\
\text { Water } \\
\text { Coverage, } \\
1990^{\mathrm{E}}\end{array}$ & $\begin{array}{c}\% \\
\text { Change } \\
\text { in } \\
\text { Improved } \\
\text { Water } \\
\text { Coverage, } \\
1990- \\
2012^{\mathrm{E}}\end{array}$ \\
\hline Portugal & 63 & 27 & 31 & 104 & 3614 & 18229 & 13.8 & 10.8 & 4.1 & 16.9 & 95.8 & 83.0 & 89.1 & 3.7 \\
\hline Russia & 93 & 39 & 36 & 95 & 30118 & 6846 & 0.4 & 13.4 & 6.2 & 32.6 & 87.1 & 33.3 & 72.7 & 3.8 \\
\hline Spain & 57 & 51 & 42 & 86 & 2377 & 25380 & 3.6 & 0.9 & 1.0 & 0.4 & 99.0 & 99.6 & 99.1 & 0 \\
\hline Thailand & 64 & 20 & 34 & 64 & 3362 & 3353 & 17.3 & 25.3 & 1.9 & 25.1 & 73.8 & 9.6 & 28.5 & 9.4 \\
\hline Turkey & 66 & 37 & 45 & 85 & 3068 & 8483 & 12.6 & 22.0 & 8.0 & 41.4 & 91.4 & 54.8 & 76.5 & 14.3 \\
\hline Uruguay & 61 & 36 & 38 & 100 & 27156 & 7423 & 5.8 & 8.8 & 4.7 & 31.8 & 94.7 & 49.1 & 89.7 & 4 \\
\hline Vietnam & 70 & 20 & 40 & 30 & 4049 & 986 & 11.4 & 16.9 & 17.3 & 9.5 & 43.2 & 0.0 & 8.8 & 33.4 \\
\hline
\end{tabular}

${ }^{\text {A }}$ Hofstede, G. Geert Hofstede | Hofstede Dimension Data Matrix. http://geert-hofstede.com/dimensions.html

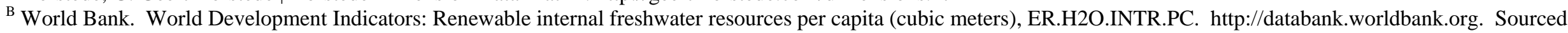
from Food and Agriculture Organization, AQUASTAT data.

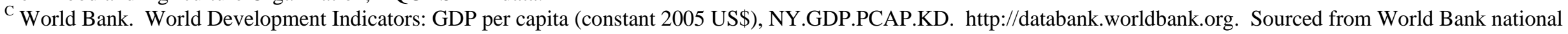
accounts data, and OECD National Accounts data files.

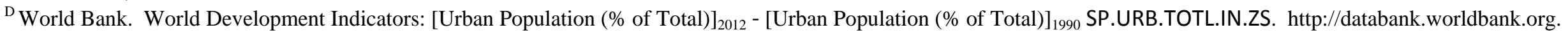
Sourced from World Bank national accounts data, and OECD National Accounts data files.

${ }^{\text {E } W H O / U N I C E F ~ J o i n t ~ M o n i t o r i n g ~ P r o g r a m m e ~(J M P) ~ f o r ~ W a t e r ~ S u p p l y ~ a n d ~ S a n i t a t i o n . ~ D a t a ~ T a b l e s: ~ I m p r o v e d ~ W a t e r, ~ P i p e d ~ o n ~ P r e m i s e s . ~ h t t p: / / w w w . w s s i n f o . o r g . ~}$ 